\title{
UPACARA PENGUBURAN PADA MASYARAKAT HINDU KAHARINGAN DI DESA \\ TEWANG TAMPANG KABUPATEN KATINGAN
}

(PERSPEKTIF HUKUM HINDU)

\author{
Oleh : Mariatie*
}

\begin{abstract}
Abstrak
Kematian menurut pandangan hukum agama Hindu Kaharingan merupakan sesuatu yang sudah diatur oleh Tuhan Yang Maha Kuasa/Ranying hatalla, dalam ajarannya tertulis pada Kitab Suci Panaturan Pasal 32 berbunyi "Ranying Hatalla Memberitahukan Kepada Raja Bunu Bagaimana tata cara mereka kembali kepada-Nya. Ayat 7 menyatakan sesungguhnya segala yang ada itu adalah berawal dari-KU, demikian pula manusia ada nafasnya ada rohnya, ada kurnia matanya, dagingnya, darahnya, kulitnya, tulang dan uratnya, nanti ia bisa kembali kepada-KU, kalau ia kembali melalui jalannya ia datang dari AKU.” (Tim Penyusun, 2013:98)

Sedangkan di dalam ajaran Hindu, manusia dan juga benda-benda fisik lainnya di alam semesta, terdiri dari lima unsur dasar, atau yang disebut dengan Panca Maha Bhuta, yaitu unsur air, api, angin, tanah, danakasa (hampa udara/ruang kosong). Apabila seseorang meninggal dunia, maka unsur-unsur penyusun tubuhnya kembali ke unsur-unsur dasar tersebut. Kematian seseorang menimbulkan kewajiban bagi orang-orang yang masih hidup untuk melakukan serangkaian upacara untuk memperlakukan jenazah, yang mana tujuannya adalah agar badan jasmaninya dapat segera dikembalikan ke unsur Panca Maha Bhuta dan atmannya dapat segera bersih dan kembali kepada Tuhan.

Upacara kematian pada masyarakat Hindu Kaharingan di Desa Tewang Tampang Kabupaten Katingan dilakukan dengan beberapa upacara mulai dari perawatan jenazah, pembuatan peti jenazah tidak bisa sembarangan harus sesuai petunjuk dan sebelum berangkat penguburan dilakukan upacara Nawekas sebagai salah satu syarat dalam rentetan upacara penguburan.
\end{abstract}

\section{Kata Kunci : Upacara, Penguburan,Hukum Hindu.}

\section{PENDAHULUAN}


Setiap Warga Negara dijamin kebebasannya memeluk dan menjalankan ajaran Agamanya seperti yang tercantum pada Pasal 29 UUD 1945. Seluruh rakyat Indonesia yakin dan percaya bahwa Tuhan itu Esa (tunggal) dan Maha Kuasa. Dengan adanya keyakinan dan kepercayaan itu, maka masyarakat Bangsa Indonesia memberikan kebebasan yang sangat mutlak dan paling azasi untuk memilih dan melaksanakan ajaran Agama sesuai dengan kepercayaannya.

Kebebasan beragama dan kepercayaan terhadap Tuhan Yang Maha Esa makin dikembangkan sehingga terbina kualitas Tri Kerukunan Umat Beragama dalam memperkokoh persatuan dan kesatuan seluruh bangsa serta meningkatkan keimanan dan ketaqwaan terhadap Tuhan Yang Maha Esa untuk bersama-sama membangun masyarakat. Salah satu upaya dalam membangun manusia Indonesia seutuhnya yaitu membentuk nilai dan sikap yang bersumber dari berbagai hal seperti agama, hukum, adat istiadat, moral dan sebagainya.

Begitu pula halnya dengan umat Hindu yang merupakan bagian dari masyarakat Bangsa Indonesia ini, tentunya mempunyai hak dan kewajiban yang sama dan setara dengan penganut agama lainnya, baik dalam hak dan kewajiban dalam menjalankan peribadatan dan

penyembahan maupun dalam pelaksanaan upacara-upacara agama lainnya seperti upacara kematian di dasari dengan keyakinan dan kepercayaannya sesuai dengan talatah atau pedoman yang diajarkan dalam agama (Upeng, Robeth, 1997:2).

Kematian menurut ajaran agama Hindu Kaharingan merupakan suatu takdir yang telah diberikan oleh Tuhan Yang Maha Kuasa/Ranying Hatalla Langit dan menjadi jalan terakhir seseorang untuk membebaskan diri dari jeratan dan tekanan kehidupan yang semakin kompleks. Kematian dipandang menjadi akhir dari penderitaan atau pembebasan, karena jika manusia telah mati maka penderitaan yang bersifat duniawi sudah putus. Karena manusia tersebut eksistensi sebagai entitas manusia telah putus dan mengalami perubahan kehidupan. Kematian adalah berakhirnya proses kehidupan, (Kamajaya, 2001: 9).

\section{PEMBAHASAN}

\section{A. Upacara Kematian Persfektif Hukum Hindu}


Agama Hindu Kaharingan percaya pada kelahiran kembali dan reikarnasi dari jiwa (atman). Jiwa yang abadi dan langgeng. Jiwa seseorang selama hidupnya akan mengalami suka dan duka serta dipengaruhi oleh hukum karma, adanya kematian adalah berawal dari adanya kelahiran. Oleh karena itu kematian bukanlah bencana besar, bukan akhir dari semua, tetapi sebuah proses alami dari sang jiwatman (atman/hambaruan) yang kemudian kembali lagi ke bumi untuk melanjutkan perjalanannya.

Dalam agama Hindu, jiwa (atman/ hambaruan) adalah bagian yang kekal tidak mengalami kematian, dia abadi. Kematian hanya dialami oleh badan fisik ini. Kematian adalah menghentikan sementaraa aktivitas fisik dan merupakan sarana bagi sang atman (Hambaruan/Panyalumpuk)Liau Haring Kaharingan,

Apa yang terjadi pada jiwa setelah kematian, tergantung pada banyak faktor antara lain

1. perbuatan sebelumnya jika seseorang telah melakukan banyak perbuatan buruk dalam hidupnya, ia akan dilahirkan kea lam yang lebih rendah dan mendapatkan penderitaan sebagai konsekuensi dari tindakannya yang jahat. Contohnya apabila dia sering mengambil tanah orang pada saat dia mau menghembus napas terakhir dia akan berteriak kesakitan mengatakan aduh saya tertimpa tanah, pada saat itulah dia merasakan menerima karma yang telah dilakukannya. Begitu pula sebaliknya apabila dia berbuat baik, dia akan pergi kea lam yang lebih tinggi dan menikmatinya dengan ketenangan.

2. Kondisi pikiran pada saat kematian adalah pikiran dan keinginan dominan dalam kesadaran mengarahkan kemana arah jiwa menuju kelahiran berikutnya, misalnya jika seseorang memikirkan keluarga dan anak-anaknya pada saat kematian sangat mungkit ia akan melakukan perjalanan menuju ke arah wisnu loka.

Kematian menurut ajaran agama Hindu Kaharingan perspektif Hukum Hindu adalah berdasarkan ajaran di dalam Kitab Suci Panaturan sebagai sumber Hukum Hindu bagi masyaraakat Hindu Kaharingan dan menjadi pedoman dalam menjalankan ajaran agama dalam hal ini tentang kematian sudah tertulis didalam Kitab Suci Panaturan Pasal 29 Ranying Hatalla berfirman kepada Raja Bunu ayat 4 menyatakan sebagai berikut : 
"Hete RANYING HATALLA bapander panjang umba Raja Bunu, tuh bitim palus panarantang aim, akan ilaluh kare manyuang Batang Petak ije jadi injapaku hayak inyewut-Ku jete Pantai Danum Kalunen tuntang panarantang aim te dapit jeha puna bagin matei".

Artinya :

Dengan panjang lebar Ranying Hatalla berfirman kepada Raja Bunu, firmannya : Untuk engkau ketahui Raja Bunu, bahwa engkau dan semua anak keturunanmu akan aku turunakn mengisi permukaan tanah bumi yang telah aku ciptakan dan Aku sebut itu Kehidupan serta bagi anak keturunanmu nantinya, ia kembali kepada-KU melalui kematian (Tim Penyusun, 2013:82).

Diperjelaskan lagi pada Pasal 32 Ranying Hatalla memberitahukan kepada keturunan Raja Bunu tata cara mereka kembali kepada-Nya, pasal 33 firmannya tentang Tiwah Suntu ketiga pasal tersebut menjadi pedoman bagi masyarakat Hindu Kaharingan melaksankan upacara kematian, karena Kematian merupakan suatu hal yang tidak dapat dihindari oleh manusia dan semua pasti akan mengalaminya. Dalam Hindu Kaharingan kematian merupakan jalan yang telah ditentukan oleh Ranying Hatalla, karena bagi Hindu Kaharingan bahwa kematian hanya sebutan bagi dunia dan secara filosofisnya manusia itu masih hidup dialam Tuhan dengan diselamatkan oleh saudara Raja Bunu yaitu Raja Sangen dan Raja Sangiang, pada saat keturunan Raja Bunu untuk kembali kepada Ranying Hatalla.

Berdasakan isi Panaturan tersebut dapat kita ketahui bahwa semua manusia telah ditakdirkan akan mengalami kematian. Dalam hal kematian ini Umat Hindu Kaharingan memiliki tata upacara dari proses jenazah, upacara penguburan, Tantulak Ambun Rutas Matei sampai pada upacara Tiwah yang sesuai menurut ajaran agama Hindu Kaharingan dan Desa, Kala Dan Patra artinya sesuai waktu, tempat, dan keadaan daerah setempat dalam pelaksanaan upacara ritualnya.

\section{B. Proses perawatan masyarakat Hindu Kaharingan}

Dalam hal kematian umat Hindu Kaharingan memiliki tata cara perawatan jenazah, dan upacara penguburan menyesuaikan dengan tempat, waktu dan keadaan (Desa,Kala dan Patra). Proses upacara kematian bagi masyarakat Hindu Kaharingan di Desa 
Tewang Tampang kabupaten Katingan adalah mulai dari seseorang menghembus napas terakhir tidak di biarkan dia berbaring sendiri tapi dipangku, kemudian telinga ditiup, supaya dia kembali pada alam Tuhan dengan keadaan baik (bujur kabujuran) meninggalkan alam semesta ini, sebelum dilakukan penguburan terlebih dahulu dilakukan perawatan Jenazah berdasarkan Buku Petunjuk Mangubur Agama Hindu Kaharingan karangan Basir Tian Agan Tahun 1999 menyatakan sebagai berikut:

\section{Memandikan Jenazah}

Yang disediakan pada saat memandikan jenazah adalah :

a. Air dalam ember

b. Sabun mandi

c. Pakaian yang akan digunakan oleh jenazah

d. Sisir, cermin, minyak, bedak

e. Piring tempat menampung rambut.

Adapun langkah yang pertama-tama yang kita lakukan dalam memandikan jenazah ini adalah mengambil air menggunakan telapak tangan disertai dengan mengucapkan mantra "Tuh anu.....aku mampandui ikai hapa danum ije barasih danum Pantis Rangkan atau Bulau Rangkan Hintan mangat ikau tuh Habalitan Bulau Hintan Buli Nyembang Ranying Hatalla Langit buli Lewu Tatau Ije Dia Rumpang Tulang Rundung Raja Kamalesu Uhat Manyak Pelek Uluh Tingang Tatu Atang Hiang”.

Setelah itu air tadi diusapkan ke jenazah, karena yang pertama tercipta dari manusia yaitu mata. Kemudian diikuti dengan menyirami seluruh anggota badan jenazah sampai merata dengan menggosokkan sabun di sekujur tubuh jenazah dengan berulang-ulang sampai benar-benar bersih.

\section{Mendandani Jenazah}

Setelah acara memandikan jenazah selesai selanjutnya dikenakan pakaian yang telah dipersiapkan dan didandani dengan bedak dibagian wajah, rambutnya disisir serta diolesi minyak seperti layaknya orang yang berdandan karena ingin 
bepergian. Setelah selesai didandani jenazah ditempatkan di bale-bale diberi galangan dengan menggunakan dua buah Gong pada bagian ujung masing-masing.

Posisi pada saat menempatkan jenazah di atas bale-bale harus memperhatikan orang yang meninggal tersebut apakah laki-laki atau perempuan. Bila yang meninggal laki-laki, maka posisi kepalanya berada di Barat mengingat asal kejadian laki-laki yang pertama berasal dari arah Laut Manggantung. Sedangkan apabila wanita maka posisi kepalanya berada di Timur, mengingat wanita berasal dari arah Hulu Batang Danum. Kemudian tangan jenazah tegak lurus berada di samping badan. Pada tangan sebelah kanan diberi telor ayam sebanyak 1 (satu) butir dan sejumlah uang yang digenggam pada tangannya. Pada kedua matanya ditutup dengan uang logam serta di bagian mulutnya diberi Lamiang, kemudian di atas jenazah ditaburi beras yang sudah diberikan warna merah dan kuning, sirih, pinang dan mangkok kecil warna putih dengan posisi telungkup.

\section{B. Proses membuat Peti Jenazah (Raung)}

Sebelum membuat peti jenazah, maka terlebih dahulu jenazah diukur dengan menggunakan rotan, yang diikuti dengan pemukulang Gong sebanyak 7 (tujuh) kali kalau yang meninggal adalah laki-laki dan sebanyak 5 (lima) kali kalau yang meninggal adalah wanita. Ketika mau berangkat harus dilengkapi dengan alat-alat seperti : beliung, parang, gergaji, piring, sendok, panci mangkok, gelas dan beras.

Sebelum menebang kayu untuk pembuatan peti, maka terlebih dahulu diadakan pemotongan ayam dan darahnya diambil untuk dicampurkan dengan beras selanjutnya untuk menaburkan pada batang kayu yang akan ditebang dengan maksud agar batang kayu tersebut tidak rusak dan dijauhkan roh-roh jahat agar tidak mengganggu orangorang yang mengerjakan peti jenazah tersebut. Sebelum peti tersebut dibawa masuk ke dalam rumah terlebih dahulu dibunyikan gong sesuai dengan jenis kelamin yang meninggal. 7 (tujuh) kali kalau yang meninggal adalah laki-laki dan sebanyak 5 (lima) kali kalau yang meninggal adalah wanita. 


\section{Proses Manyaluh Raung (Peti Jenazah)}

Setelah Raung (peti jenazah) sudah siap, maka setelah tinggal satu hari lagi jenazah dimasukkan ke dalam raung akan diadakan upacara terlebih dahulu. Waktu memasukkan jenazah ke dalam Raung ada tiga syarat yang harus disediakan, yaitu :

1. Serbuk Nyating (serbuk damar)

2. Tamiang (tamiang adalah sejenis bambu)

3. Baliung (beliung)

Manyaluh Raung adalah prosesi mensucikan Raung secara spiritual yang dilakukan oleh Pisor atau orang yang dituakan dan menghidupkan bambu Tamiang sejenis bambu yang telah berisi serbuk damar lalu diayunkan mengelilingi Raung sesuai dengan jenis kelamin yang meninggal (7 (tujuh) kali kalau yang meninggal adalah lakilaki dan sebanyak 5 (lima) kali kalau yang meninggal adalah wanita) kemudian memukul-mukulkan isi beliung di Raung seraya mengucapkan mantra.

\section{Proses memasukan Jenazah ke dalam Raung (peti jenazah)}

Memasukkan jenazah ke dalam Raung (peti jenazah) diiringi dengan taburan beras merah dan kuning dicampurkan dengan giling pinang rukun tarahan (sirih, pinang dan rokok) diiringi dengan pemukulan gong (nitih) sebayak $3 \mathrm{x}$.

Pihak keluarga alamarhum semua berkumpul untuk melihat yang terakhir sebelum ditutup peti jenazah tersebut.

\section{E. Proses Penguburan pada kematian masyarakat Hindu}

\section{Kaharingan}

Upacara penguburan berasal dari kata upacara dan mangubur. Kata Upacara berasal dari kata "Upa" yang berarti dekat dan "Cara" yang berarti tradisi atau kebiasaan yang merupakan tingkahlaku manusia baik perorangan maupun kelompok masyarakat yang didasarkan pada kaidah-kaidah hukum yang berlaku.Sedangkan mengubur berasal dari 
kata 'Kubur' yang berarti kuburan. Jadi upacara mangubur adalah upacara menanamkan jenazah ke liang kubur. Bagi umat Hindu Kaharingan apabila seseorang meninggal dunia wajib diupacarakan sesuai tradisi setempat. Dalam agama Hindu Kaharingan ritual kematian tidak hanya sampai pada ritual penguburan, namun masih memiliki beberapa tahapan lagi menyesuaikan dengan tradisi masing-masing daerah, misalkan untuk umat Hindu Kaharingan di Desa Tewang Tampang Kabupaten Katingan setelah selesai rangkaian acara pemakaman dilanjutkan dengan acara Ngarak Hinau, upacara mamapas pali (pantangan / ambun rutas matei) dan sampai 3 (tiga) bulan setelah penguburan dilakukan upacara Ngalangkang Kubur artinya membersihkan tempat kuburan dan memberikan sesajaen sebagai persembahan dan terakhir dilakukan adalah upacara Tiwah sebagai rukun kematian tingkat terakhir. Sementara untuk DAS Katingan terdiri dari rangkaian acara pemakaman, mamapas Pali, Nyorat dan Tiwah.

Dalam penguburan dilakukan beberapa tahapan sebagai berikut :

\section{Berangkat Menggali Kubur}

Yang harus disiapkan sebelum menggali kubur terbagi atas dua syarat yaitu :

a. Beras berwarna merah, kuning yang dicampurkan dengan giling pinang (sirih, pinang).

b. Beras dicampur dengan darah mentah.

Setelah sampai di kuburan, sebelum menggali kuburan yang pertama kali dilakukan yaitu menabur beras merah kuning yang dicampur giling pinang dan rokok tujuannya memberitahukan kepada Raja Entai Nyahu dengan Kameluh Tantan Dandayu yang tinggal di Tahanjungan Bukit Pasahan Raung Kereng Dadarian Sapendang lunuk Tarung (kuburan).

Lalu setelah itu menabur beras dicampur dengan darah mentah yang tujuannya untuk Kamben Kambe Ngarungkung Sale, Kamben Lemba Nalawung Jela, Siak Sakung Malik Malem, Sirat Pasat Ngarungkung Tabuni, akan kare ganan bahutai diar (untuk para buta kala) agar mereka semua menerima beras campur darah mentah agar mereka tidak mengganggu semua kegiatan ritual sehingga upacara penguburan berjalan lancar. 


\section{Pelaksanaan Upacara Mangubur (pemakaman)}

Pada saat pemakaman dilaksanakan diakukan dalam dua tahap yaitu:

1) Mampaluan Raung Bara Huma (Mengeluarkan peti jenazah dari rumah duka) sebelum peti jenazah dibawa keluar rumah duka terlebih dahulu disiapkan sarana sebagai berikut :

a. Danum Karak yaitu air yang dicampur dengan kerak nasi.

b. Tampung Papas (sarana mamapas yang terdiri dari daun andung/sawang gagar dan daun kayu tungkun).

c. Darah hewan korban

d. Beras Tawur (beras berwarna merah dan kuning karena dicampur dengan kunyit)

e. Giling Pinang, Rukun Tarahan

f. Bua Baluh (kendi berisi air)

g. Sumbu (lampu teplok)

Setelah semua sarana telah siap maka peti jenazah dibawa ke depan pintu rumah dengan posisi, kalau yang meninggal laki-laki maka kepalanya ke arah luar tetapi jika yang meninggal perempuan maka kepalanya dalam posisi ke dalam rumah. Kemudian dilanjutkan dengan Mamapas Raung (mensucikan peti jenazah) dengan sarana Danum Nyanyah (air cucian beras) dan tampung papas yang disertai desertai dengan mantra kemudian peti jenazah diayun-ayunkan keluar masuk ditengah-tengah pintu sebanyak 7 (tujuh) kali kalau yang meninggal adalah lakilaki dan sebanyak 5 (lima) kali kalau yang meninggal adalah wanita disertai dengan pemukulan gong. Bila peti jenazah sudah keluar, maka kendi berisi air langsung dipecahkan di depan pintu rumah supaya sial itu habis dibawanya. Peti jenazah langsung dibawa ketempat peristirahatan terakhir.

2) Peti jenazah (Raung) berada di pemakaman

a. Menyerahkan jenazah kepada Raja Entai Nyahu (dewa penunggu kuburan) 
b. Peti jenazah(Raung) diletakkan di atas liang kubur dan ditopang galangan kayu supaya almarhum diserahkan kepada Raja Entai Nyahu (dewa penunggu kuburan)

c. Acara penyerahan jenazah (Raung) kepada Raja Entai Nyahu (dewa penunggu kuburan) dipimpin oleh seorang Basir/Rohaniawan dilaksanakan dengan cara manawur (menabur beras tawur) yang telah disipkan, bertujuan agar almarhum diterima menyatu dengan Ranying Hatalla Langit (Tuhan).

3) Acara pemakaman

a. Setelah acara menyerahkan jenazah(Raung) kepada Raja Entai Nyahu (dewa penunggu kuburan) langsung diadakan upacara pemakaman.

b. Dalam acara pemakaman peti jenazah (Raung) dimasukkan ke liang kubur lalu ditimbun dengan tanah dan langsung ditancapkan Sampalaki (batu nisan) delanjutkan dengan menghidupkan dan mematikan lampu tembok yang dibawa sebanyak tiga kali berturut-turut disertai dengan mantra.

\section{PENUTUP}

Berdasarkan penulisan diatas dapat disimpulkan sebagai berikut :

1. Kematian menurut ajaran agama Hindu Kaharingan perspektif Hukum Hindu adalah berdasarkan ajaran di dalam Kitab Suci Panaturan sebagai sumber Hukum Hindu bagi masyaraakat Hindu Kaharingan dan menjadi pedoman dalam menjalankan ajaran agama dalam hal ini tentang kematian sudah tertulis didalam Kitab Suci Panaturan Pasal 29 Ranying Hatalla berfirman kepada Raja Bunu, pasal 32 Ranying Hatalla memberitahukan kepada keturunan Raja Bunu tata cara mereka kembali kepada-Nya, pasal 33 firmannya tentang Tiwah Suntu ketiga pasal tersebut menjadi pedoman bagi masyarakat Hindu Kaharingan melaksankan upacara kematian, karena kematian merupakan suatu hal yang tidak dapat dihindari oleh manusia dan semua pasti akan mengalaminya. Dalam Hindu Kaharingan kematian merupakan jalan yang telah ditentukan oleh Ranying Hatalla, karena bagi Hindu Kaharingan bahwa kematian hanya sebutan bagi dunia dan secara filosofisnya manusia itu masih hidup di alam Tuhan 
dengan diselamatkan oleh saudara Raja Bunu yaitu Raja Sangen dan Raja Sangiang, pada saat keturunan Raja Bunu untuk kembali kepada Ranying Hatalla.

2. Proses kematian melalui beberapa proses tahapan yaitu perawatan Jenazah, membuat peti Jenazah (Raung), Manyaluh Raung (peti jenazah), memasukan Jenazah ke dalam Raung (Peti Jenazah), dan proses penguburan.

Daftar Pustaka

Agan Tian. 1999. Petunjuk Mangubur Agama Hindu Kaharingan. Palangka Raya: MB-AHK. Kamajaya. 2001. Alama kehidupan sesudah mati. Surabaya: paramita.

Kabinet Kerja Periode 2014-2019, Undang-Undang Dasar Negara Republik Indonesia 1945 dengan Penjelasannya, Surabaya: Penerbit Cahaya Agency.

Upeng, Robeth, 1997. Buku Upacara Tiwah Dayak Ngaju Kalimantan Tengah, Palangkaraya : Lemnit Unpar.

Tim Penyusun. 2013. Panaturan. Denpasar: Widya Dharma 